\title{
CXCL12 loaded-dermal filler captures CXCR4 expressing melanoma circulating tumor cells
}

\author{
Caterina leranò ${ }^{1}$, Crescenzo D’Alterio ${ }^{1}$, Simona Giarra², Maria Napolitano', Giuseppina Rea', Luigi Portella', \\ Assunta Santagata ${ }^{1}$, Anna Maria Trotta ${ }^{1}$, Antonio Barbieri ${ }^{3}$, Virginia Campani ${ }^{2}$, Antonio Luciano ${ }^{3}$, Claudio Arra ${ }^{3}$, \\ Anna Maria Anniciello ${ }^{4}$, Gerardo Botti ${ }^{4}$, Laura Mayol ${ }^{2}$, Giuseppe De Rosa ${ }^{2}$, Roberto Pacelli ${ }^{5}$ and Stefania Scala ${ }^{1}$
}

\begin{abstract}
Development of distant metastasis relies on interactions between cancer and stromal cells. CXCL12, also known as stromal-derived factor 1a (SDF-1a), is a major chemokine constitutively secreted in bone marrow, lymph nodes, liver and lung, playing a critical role in the migration and seeding of neoplastic cells. CXCL12 activates the CXCR4 receptor that is overexpressed in several human cancer cells. Recent evidence reveals that tumors induce pre-metastatic niches in target organ producing tumor-derived factors. Pre-metastatic niches represent a tumor growth-favoring microenvironment in absence of cancer cells. A commercially available dermal filler, hyaluronic acid (HA) -based gel, loaded with CXCL12 (CLG) reproduced a "fake" pre-metastatic niche. In vitro, B16-hCXCR4-GFP, human CXCr4 expressing murine melanoma cells efficiently migrated toward CLG. In vivo, CLGs and empty gels (EGs) were subcutaneously injected into C57BL/6 mice and 5 days later B16-hCXCR4-GFP cells were intravenously inoculated. CLGs were able to recruit a significantly higher number of B16-hCXCR4-GFP cells as compared to EGs, with reduced lung metastasis in mice carrying CLG. CLG were infiltrated by higher number of CD45-positive leukocytes, mainly neutrophils CD11b+Ly6G+ cells, myeloid CD11b+Ly6G- and macrophages F4/80. CLG recovered cells recapitulated the features of B16-hCXCR4-GFP (epithelial, melanin rich, MELAN A/ S100/ c-Kit/CXCR4 pos; a-SMA neg). Thus a HAbased dermal filler loaded with CXCL12 can attract and trap CXCR4+tumor cells. The CLG trapped cells can be recovered and biologically characterized. As a corollary, a reduction in CXCR4 dependent lung metastasis was detected.
\end{abstract}

\section{Introduction}

Cancer metastases contribute to over $90 \%$ of cancer deaths. The metastatic process is a complex process that involves primary tumors, tumor microenvironment and distant organs ${ }^{1,2}$. Recent studies suggest that stromal cells control the effective organ colonization and growth of circulating tumor cells (CTCs) ${ }^{1}$. CXCL12, also known as

\footnotetext{
Correspondence: Stefania Scala (scalaste@gmail.com) (s.scala@istitutotumori.na.it) ${ }^{1}$ Functional Genomics, Istituto Nazionale Tumori - IRCCS - Fondazione "G. Pascale", Napoli, Italy

${ }^{2}$ Department of Pharmacy, Federico II University, Napoli, Italy

Full list of author information is available at the end of the article.

Edited by G. Ciliberto
}

stromal-derived factor $1 \alpha$ (SDF-1 $\alpha)$, is a major chemokine, constitutively secreted in bone marrow, lymph nodes, liver and lung ${ }^{3}$; it plays a key role in physiologic processes, such as lymphocyte homing, chemotactic migration, ${ }^{4,5}$ and metastatic development ${ }^{6}$. CXCL12 binds the chemokine receptor, CXCR4, overexpressed in at least 23 different human cancers ${ }^{7-9}$ and CXCR7, a recently identified CXCL12 receptor also overexpressed in tumors $^{10-12}$. Fibroblasts remodel extracellular matrix $(\mathrm{ECM})$ at the pre-metastatic niche, a tumor growthfavoring microenvironment developed in the absence of neoplastic cells ${ }^{13-15}$, secreting inflammatory cytokines and growth factors such as CXCL12, TGF- $\beta$, S100A4, and

\section{(c) The Author(s) 2019}

(c) (i) Open Access This article is licensed under a Creative Commons Attribution 4.0 International License, which permits use, sharing, adaptation, distribution and reproduction cc) in any medium or format, as long as you give appropriate credit to the original author(s) and the source, provide a link to the Creative Commons license, and indicate if changes were made. The images or other third party material in this article are included in the article's Creative Commons license, unless indicated otherwise in a credit line to the material. If material is not included in the article's Creative Commons license and your intended use is not permitted by statutory regulation or exceeds the permitted use, you will need to obtain permission directly from the copyright holder. To view a copy of this license, visit http://creativecommons.org/licenses/by/4.0/. 
expressing fibronectin and matrix metalloproteinases $(\mathrm{MMPs})^{16}$. Tumor-secreted factors regulate the expression of molecules such as S100A8, S100A9, LOX, fibronectin, MMP-9, MMP- ${ }^{17}$ that promote the recruitment of specific bone marrow-derived cells (VEGFR1+, CD11b+, $\mathrm{CD} 34+)$, myeloid cells (CD11b+) as well as differentiated innate and adaptive immune cells ${ }^{17,18}$. In the ECM, CXCL12 interacts with heparin sulfates ${ }^{19}$ and co-localizes with hyaluronic acid (HA) ${ }^{20-22}$; hematopoietic progenitor cells that migrate on HA toward a gradient of CXCL12 acquire spread and polarization expressing CD44 receptor mainly at the leading edge ${ }^{22,23}$. Hyaluronic acid (HA, or hyaluronan) is a glycosaminoglycan which consists of regular repeating non-sulfated disaccharide units of glucuronic acid and $\mathrm{N}$-acetyl glucosamine that exhibits no tissue or species specificity ${ }^{24}$. HA is a principal component of the extracellular matrix, interacts with specific cell surface receptors (CD44, RHAMM and ICAM-1) and contributes to cell-cell adhesion, migration, proliferation and differentiation ${ }^{25,26}$. Injectable hyaluronic acid (HA) gels such as Intense Belotero ${ }^{\circledR}$ dermal filler are used in aesthetic medicine and thought to be applicable as injectable drug delivery systems ${ }^{26}$. CXCL12, cationic chemokine, binds to glycosaminoglycans (GAGs) through ionic interactions between basic amino acid residues and acidic groups along the disaccharide backbone ${ }^{27}$. Since CXCL12 is highly unstable and rapidly inactivated by CD26, several drug delivery systems have been developed to improve its in vivo residence time $^{28}$. Polymeric hydrogels can hide and protect chemokines from enzymatic cleavage and glycosaminoglycans (GAGs) immobilize and enhance chemokines local concentrations, promoting oligomerization and improving of presentation to the receptors ${ }^{29,30}$. HA, abundant in the bone marrow where CXCL12 is expressed, serves as an anchoring molecule for breast metastatic cells homing through the CD44 receptor ${ }^{22,31}$ Taking advantage of CXCR4 expression on metastatic, aggressive cells we speculate that an artificial tool loaded with CXCL12 might establish a condition similar to pre-metastatic niche that with recruitment of neutrophils and bone marrow derived cells will attract B16-hCXCR4 cells diverting them from secondary metastatic sites. Herein a commercially available dermal filler, HA-based gel, loaded with CXCL12 reproduced a "fake" pre-metastatic niche. The efficacy of this tool was evaluated in (i) recruiting circulating cells to be biologically characterized; (ii) trapping tumor cells and consequently reducing metastases.

\section{Materials and methods Cell culture}

B16 cells were transfected with $5 \mu \mathrm{g}$ of pCMV6-ACGFP Vector (TrueORF clone; Origene) or with $5 \mu \mathrm{g}$ of pCMV6-AC-h-CXCR4-GFP Vector (TrueORF clone;
Origene). B16-GFP and B16-hCXCR4-GFP murine melanoma cells were grown at $37^{\circ} \mathrm{C}$ in $5 \% \mathrm{CO} 2$ in IMDM with $10 \% \mathrm{FBS}$ and $2 \mathrm{mM}$ glutamine, $50 \mu \mathrm{g} / \mathrm{mL}$ penicillin, $50 \mu \mathrm{g} / \mathrm{mL}$ streptomycin and $2 \mathrm{mg} / \mathrm{mL}$ G418. B16hCXCR4-GFP cells were stained with Cell Tracker Green CMFDA at concentration of $10 \mathrm{mM}(10.8 \mu \mathrm{l}$, anhydrous DMSO). Cell Tracker Green CMFDA solution $(1 \mu \mathrm{l})$ was added to the cells suspended in serum-free medium $\left(4 \mathrm{ml}\right.$ ) and incubated for $30 \mathrm{~min}$ at $37^{\circ} \mathrm{C}$ (Life Technologies). Cell line was morphologically identified monthly.

\section{Gel preparation}

The commercially available HA based gels (Belotero Intense ${ }^{\circledR}$ ) were purchased by Merz Pharma. HA fillers were commercially packaged in sterile ready-to-go syringes and appear as a clear, colorless, low-viscosity gels. The recombinant human/ CXCL12/SDF-1 alpha (R\&D System) $(300 \mathrm{ng} / \mathrm{ml})$ in PBS/ 0.5\% BSA was dropped onto the sterile gel, gently mixed by using a micropipette without introducing bubbles and immediately used. For in vivo experiments, CXCL12 $(5 \mu \mathrm{g} / \mathrm{ml})$ in $100 \mu \mathrm{l}$ was dropped onto the sterile gel $(1 \mathrm{ml})$ and immediately injected in the subcutaneous flank of C57BL/6 mice.

\section{Migration}

B16-GFP and B16-hCXCR4-GFP cells ( $2 \times 10^{5} /$ well) were seeded on 24 -well transwell inserts $(8 \mu \mathrm{m}$ pore-size $)$ in culture medium containing $0.5 \%$ BSA with or without the CXCR4 antagonist AMD3100 (Sigma) (10-100 nM), antiCXCR7 (11G8, R\&D System) $(10 \mu \mathrm{g} / \mathrm{ml})$. Cells were allowed to migrate for $18 \mathrm{~h}$ toward BSA $0.5 \%$, CXCL12 $(300 \mathrm{ng} / \mathrm{ml})$, CXCL12 (300 ng/ml) loaded in gel (CLG), and empty gel (EG). Some migrations were evaluated at later time points $(3,7,14,21,28$ days). The cells were fixed in 4\% (w/v) paraformaldehyde in PBS and stained for 15 min with DAPI. Cells that had migrated to the bottom side of the membrane were visualized under the fluorescent microscope (Carlo Zeiss, Axio Scope.A1) and counted (cells in five randomly chosen visual fields). Migration was reported as migration index, the number of cells migrating toward CXCL12 or CLG /number of cells migrating toward BSA $0.5 \%$ medium or EG. The cells migrating inside the gels were assessed by fluorescence microscopy (Carlo Zeiss, Axio Scope.A1).

\section{In vivo metastases assay}

CXCL12 (5 $\mu \mathrm{g} / \mathrm{ml})$-loaded gels (CLGs) and empty gels (EGs) were injected in the subcutaneous flank of 18 (9/ group) 6-8-week-old female C57BL/6 mice (Harlan). Five days later $5 \times 10^{5}$ B16hCXCR4-GFP cells were inoculated into the tail vein. The mice were divided into three groups: (I) control mice (no gels) (6/group), (II) mice inoculated with empty gels (EG) (9/group), (III) mice 
inoculated with CXCL12-loaded gels (CLG) (9/group). Mice were sacrificed 22 days post-cell injection; lungs and gels were analyzed. Gels were digested with hyaluronidase (HAase, Bioindustria) (100 Units $/ \mathrm{ml}$ ) in 4 Units $/ \mathrm{ml}$ in PBS. Lungs were fixed in $10 \%$ buffered formalin, paraffinembedded and hematoxylin/eosin stained. Microscopic analysis was conducted with a computer-assisted image measurement program by a microscope (BX51 microscope and DP-1 microscope digital camera; Olympus Japan). On days 10 and 22 post cells injection mice were anesthetized with pentobarbital $(70 \mathrm{mg} / \mathrm{kg})$ and subjected to retro-orbital blood sampling. Blood was collected using $1 \mathrm{ml}$ syringes with $10 \mu \mathrm{l}$ fresh EDTA (Spinreact) and processed for detection of the circulating tumor cells (CTCs). The Istituto Nazionale Tumori, IRCCS, Fondazione Giovanni Pascale Independent Ethical Committee approved the study and experiments were performed in accordance with the Institutional Animal Care and Use Committee guidelines.

\section{Gels (CLG/EG) characterization}

CXCL12 $(5 \mu \mathrm{g} / \mathrm{ml})$-loaded gels (CLGs) and empty gels (EGs) were injected in the subcutaneous flank of 24 (12/ group) 6-8-week-old female C57BL/6 mice (Harlan). The mice were sacrificed at: $24 \mathrm{~h}$ after gel implantation, before B16-hCXCR4-GFP cells inoculation; at $72 \mathrm{~h}$ and 21 days post B16-hCXCR4-GFP cells inoculation. Hydrogels were fixed in $10 \%$ buffered formalin, paraffin-embedded as previously described ${ }^{32,33}$, sectioned into $3-\mu \mathrm{m}$ slices and stained with haematoxylin/eosin. Gels infiltrating cells were quantified as cells $/ \mathrm{mm}^{2}$ by in 5 consecutive highpower field (HPF) with $400 x$ magnification $\left(0.237 \mathrm{~mm}^{2} /\right.$ field), using an Olympus BX51 microscope (Olympus, Tokyo, Japan). Slides were incubated with the following primary Abs by overnight incubation at $4{ }^{\circ} \mathrm{C}$ : Rabbit polyclonal to anti-mouse CD11b (E-AB-70017, dilution 1:300, Elabscience with heat-induced epitope retrieval (HIER) pH9 pre-treatment); Rabbit polyclonal to antimouse CD11c (E-AB-70016, dilution 1:200, Elabscience with heat-induced epitope retrieval (HIER) pH6 pretreatment); rat monoclonal anti-mouse F4/80 (clone CI: A31, dilution 1:100, Biorad with HIER pH6 pre-treatment); rat monoclonal anti-mouse Ly6G (clone 1A8, dilution 1:1000, BD Becton, Dickinson and Company, with HIER pH6 pre-treatment) polyclonal biotinylated rabbit anti-rat Ig (Dako E0468 1:400 for $60 \mathrm{~min}$ at RT) were used as a secondary $\mathrm{Ab}$. UltraVision ${ }^{\mathrm{Tm}}$ Detection System: HRP Polymer/AEC Chromogen (ThermoScientific) was used for visualization of staining according to the manufacturer's instructions. The infiltrated cells were scored according to $\mathrm{H}$-score (percentage of cells with staining $\mathrm{X}$ intensity value scored from 0 for "no signal" to 3 for "strong signal") ${ }^{34}$ The evaluation of stained immune cells was performed in duplicate blindly by three independent observers.

\section{Flow cytometer analyses}

Tumoral cells recovered from gels were stained with a PE-hCXCR4 and APC anti-mouse CD45 Ab (BD Biosciences) and analyzed with a FacsDiva software 8.18 (BD Bioscience). The cells were stained with a viability dye 7AAD to identify living and dead cells. The percentage of CXCR4 positive/ GFP positive cells was evaluated on live cells, 7-AAD negative / CD45 negative cells gate. Single stained samples were performed for compensation controls, and isotype control was used to determine the level of non-specific binding. Red blood cells in $100 \mu$ l murine blood cells were lysed and remaining cells were stained with human CXCR4 antibody (clone 11G5), PE-hCXCR4, and APC anti-mouse CD45 Ab (clone 30-F11, BD Biosciences). Also, EG/CLG hydrogels were recovered and digested with hyaluronidase. Cells were stained using 7AAD (Thermo-Fisher), APC anti-mouse CD45 Ab (BD Biosciences), PE-Cy7 anti-mouse Ly-6G (clone1A8 BD Biosciences) and AlexaFluor 488 anti-mouse CD11b (clone M1/70, Elabscience). Lymphocytes were characterized as CD45 bright/ SSC low on base of cell scattering characteristics and $\mathrm{CD} 45$ expression.

\section{Cell viability analysis}

B16-CXCR4-GFP cells were allowed to migrate onto gels at 3, 7, 14, 21 and 28 days. Gels were digested with hyaluronidase as above described, cells recovered and dissociated with $0.05 \%$ trypsin/EDTA. Cell suspension was incubated with $10 \mu \mathrm{L}$ of trypan blue solution and live cells counted on hemocytometer.

\section{Immunofluorescence}

Cells $\left(1 \times 10^{4}\right)$ were seeded on glass coverslips, fixed with $4 \%$ paraformaldehyde $\left(15 \mathrm{~min}, 4^{\circ} \mathrm{C}\right)$ and stained with mouse anti-human CXCR4 primary antibody (clone 12G5 R\&D), rabbit anti-cKit primary antibody, mouse anti$\alpha$ SMA primary antibody, mouse anti-S100 primary antibody and mouse anti-Melan A primary antibody; Alexa Fluor goat anti-mouse 594-conjugated secondary antibody, or Alexa Fluor goat anti-rabbit 488-conjugated secondary antibody, sequentially. DAPI was used to stain the cell nucleus (Carlo Zeiss, Axio Scope.A1).

\section{Real time PCR}

Total RNA from murine blood (100 ul) was extracted using QIAamp RNA Blood Mini Kit (Qiagen), according to the manufacturer's instructions. DNase-treated RNA (100 ng) was reverse transcribed by Superscript II RNase H-reverse transcriptase according to the manufacturer's instructions (Invitrogen-Life Technologies, Carlsbad, CA, USA). 
Real time-PCR was carried out using about $12.5 \mathrm{ng}$ of cDNA in $25 \mu \mathrm{l}$ final of SYBR Green reaction mixture. An CFX96 Touch ${ }^{\mathrm{Tm}}$ Real-Time PCR Detection System (BioRad) robocycler was used for the amplification. For turbo-GFP, cycling conditions of the PCR were as follows: initial denaturation $\left(10 \mathrm{~min}\right.$ at $\left.95^{\circ} \mathrm{C}\right)$ followed by 40 cycles of denaturation $\left(10 \mathrm{~s}\right.$ at $\left.95^{\circ} \mathrm{C}\right)$, annealing $\left(30 \mathrm{~s}\right.$ at $\left.58^{\circ} \mathrm{C}\right)$ synthesis $\left(30 \mathrm{~s}\right.$ at $\left.72^{\circ} \mathrm{C}\right)$. The gene-specific primers used for the amplification were as follows: mc-kit $5^{\prime}$-TCATCGAGTGTGATGGGAAA-3' (forward), 5' - GGTGACTT GTTTCAGGCACA-3' (reverse); m $\alpha$ SMA 5' - TGACCCA GATTATGTTTGA-3' (forward), 5' - GCTGTTATAGGT GGTTTCG- $3^{\prime}$ (reverse); $\mathrm{m} \beta$ actin $5^{\prime}$ - AGGCTGTG CTGTCCCTGTAT-3'(forward), 5' - AAGGAAGGCTGG AAAAGAGC-3' (reverse); Turbo GFP 5'-AGGACA GCGTGATCTTCACC-3' (forward), 5' - CTTGAAGTGC ATGTGGCTGT-3' (reverse); mGAPDH 5'-TCTCCA GGCGGCACGTC-3' (forward); 5'-TGGCCTTCCGT GTTCCTACCC-3' (reverse). Subsequently, TurboGFP mRNA was quantified comparing its expression to mGAPDH mRNA levels. Samples were run in triplicate.

\section{CXCL12/SDF-1a plasma concentration}

Blood samples were obtained from retroorbital sinus of anesthetized mice in EDTA and stored at $-70^{\circ} \mathrm{C}$ until assayed. Mouse SDF- $1 \alpha$ was evaluated with CXCL12 $\alpha$ Sandwich- ELISA kit (e-Bioscience).

\section{Statistical analysis}

Student's $t$-tests were used to compare the means of two groups when the assumptions of normality assessed with the Shapiro-Wilks test are met. For independent (unpaired) groups which are non-normally distributed, the non-parametric Mann-Whitney $U$ test was used. The non-parametric Kruskal-Wallis test, used in the in vivo experiments, evaluated the significance of the differences of the mean ranks, owing to a lack of compatibility to the normal distribution. Per-comparison two-sided $p$ values less than 0.05 were considered statistically significant. The values given are means \pm standard deviation (SPSS statistics).

\section{Results}

\section{CXCL12 loaded gel (CLG) attracted CXCR4 positive cells}

With the intent to attract CXCR4 expressing neoplastic cells a commercially available HA based gel (Belotero Intense $^{\circledast}$ ) loaded with CXCL12 was developed (CXCL12loaded gel; CLG /empty gel; EG). B16-hCXCR4-GFP cells strongly express human CXCR4 (Supplemental Fig. 1A) and, when injected intravenously, develop lung metas$\operatorname{tases}^{35}$. The B16-hCXCR4-GFP cells were stained with Cell Tracker Green and allowed to migrate toward medium containing CXCL12 (300 ng/ml) or CLG loaded with 300 ng/ml CXCL12. In Fig. 1A, B16-hCXCR4-GFP cells migrated toward CLG with a rate similar to that obtained with soluble CXCL12 (Migration Index respectively, $2.81 \pm 0.32$ vs $2.80 \pm 0.52$ ). Migration was specifically inhibited by AMD3100 (Fig. 1A), the unique CXCR4 antagonist clinically approved ${ }^{36}$ but not inhibited by antiCXCR7 (clone 11G8) suggesting that $\mathrm{CXCR7}^{37}$ is not involved in B16-hCXCR4-GFP CXCL12-induced migration. Anti-CXCR7 (clone 11G8), as the small molecule CXCR7 inhibitor $\mathrm{CCX}_{771}{ }^{38}$, was highly selective for CXCR7, specifically inhibited CXCL12-dependent migration and competed with CXCL11/CXCL12 binding in CXCR7 expressing MCF-7. (Supplemental Fig. 1B). B16-hCXCR4-GFP migration was also compared to B16GFP cells (hCXCR4 negative) migration. In Fig. 1B, B16hCXCR4-GFP cells migrated more efficiently than B16GFP towards CXCL12 or CLG; B16-GFP cells comparably migrated toward CXCL12 (Migration index, $1.57 \pm 0.27$ ) or CLG (Migration index, $1.54 \pm 0.32$ ). Same experiments were conducted with CCRF-CEM, T cell leukemia cells (Supplemental Fig. 2, A) and A498, human renal cancer cells $^{12}$ (Supplemental Fig. 3).

\section{CXCL12 released from CLG induces long term chemotaxis}

To investigate the efficacy of CLG-trapped CXCL12 to induce chemotaxis, the B16-hCXCR4-GFP migration toward CLG or EG was evaluated at longer time points. As shown in Fig. 1C B16-hCXCR4-GFP cells specifically migrated toward CLG as compared to EG for 14 days. At 21 and 28 days there were no detectable differences in migration toward CLG or EG suggesting CXCL12 exhaustion. Thus CXCL12 embedded into the gel is able to attract CXCR4 expressing cells. These data were confirmed by the slow in vitro CXCL12 release from CLG [5.43\% of the total loaded cytokine released after 7 day incubation (up to $100 \mathrm{~h}$ ) (data not shown)].

\section{B16-hCXCR4-GFP cells trapped in EG or CLG gels progressively die}

To evaluate the viability and the growth capability of B16-hCXCR4-GFP trapped cells, the gels were digested and cells recovered. In Fig. 2, trypan-blue exclusion test demonstrated that recovered cells were viable at three days. In CLG, on day 14 approximately $30 \%$ of live cells and $70 \%$ of dead cells were detected while in EG the percentage of live cells was $14 \%$ and dead cells was $86 \%$. After four weeks the majority of cells were dead in all gels.

\section{CLG in vivo captured Circulating Tumor Cells (CTCs)}

To investigate the efficacy of CLG in attracting CXCR4 positive circulating tumor cells, the syngeneic model of melanoma lung metastasis was employed. CLG [CXCL12 $(5 \mu \mathrm{g} / \mathrm{ml})$ in $100 \mu \mathrm{l}]$ was subcutaneously injected into the right flank of C57BL/6 female mice. Five days later B16hCXCR4-GFP cells $\left(5 \times 10^{5}\right)^{39,40}$ were intravenously 

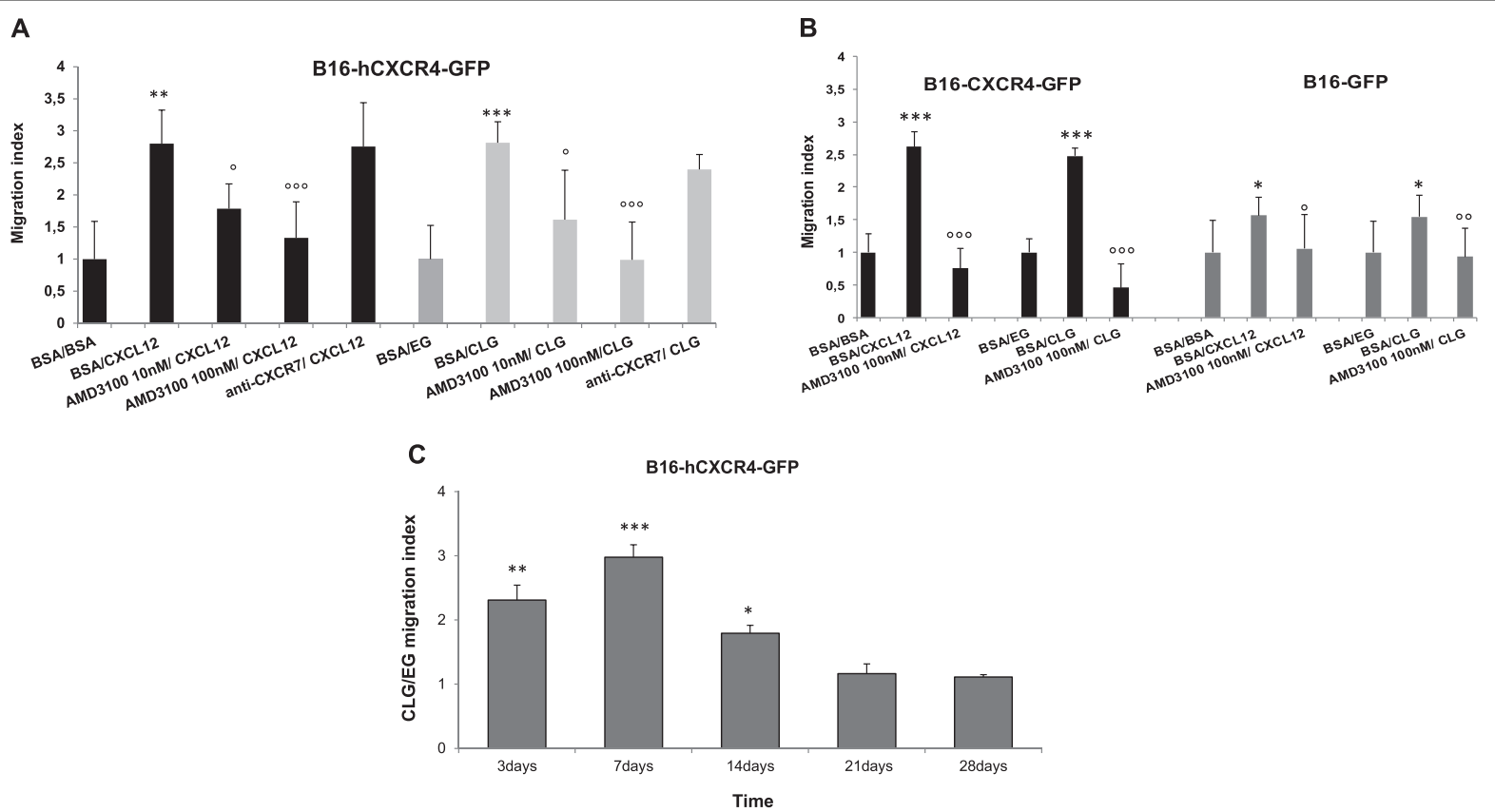

Fig. 1 CXCL12 loaded gel (CLG) attracted CXCR4 positive cells. A Migration of B16-hCXCR4-GFP cells Cell Tracker Green toward CXCL12 in culture medium or CLG $(300 \mathrm{ng} / \mathrm{ml})$ with AMD3100 $(10-100 \mathrm{nM})$ or anti-CXCR7 $(10 \mu \mathrm{g} / \mathrm{ml})$. The results are expressed as index (B16-hCXCR4-GFP cells migrated toward CXCL12 or CLG/ B16-hCXCR4-GFP cells migrated toward BSA (0.5\% BSA in culture medium) or EG). Each column represents the mean \pm S.D. $(n=3)$. Statistical significances were calculated by Mann-Whitney U test. ${ }^{* *} p<0.01 \mathrm{CXCL} 12$ vs BSA or ${ }^{* * *} p<0.001 \mathrm{CLG}$ vs EG; ${ }^{\circ} p<0.05 ;{ }^{\circ 00}$ $p<0.001$ AMD3100 vs CXCL12 or AMD31000 vs CLG. B Migration assay of B16-hCXCR4-GFP and B16-GFP cells. B16-hCXCR4-GFP cells and B16-GFP were exposed to the chemokine CXCL12 in culture medium or CLG $(300 \mathrm{ng} / \mathrm{ml})$ with AMD3100 $(100 \mathrm{nM})$ in a transwell culture plate. The results are expressed as index. Each column represents the mean \pm S.D. $(n=3)$. Statistical significances were calculated by Student's $t$-test. In B16-hCXCR4-GFP cells ${ }^{* *} p<0.001$ CXCL12 vs BSA or CLG vs EG; ${ }^{000} p<0.001$ AMD3100 vs CXCL12 or AMD31000 vs CLG; in B16-GFP * $p<0.05$ CXCL12 vs BSA or ${ }^{*} p<0.05$ CLG vs EG; ${ }^{\circ} p<0.05$ AMD3100 vs CXCL12 or ${ }^{\circ} p<0.01$ AMD31000 vs CLG. C Long term migration of B16-hCXCR4-GFP cells Cell Tracker Green toward CLG $(300 \mathrm{ng} / \mathrm{ml})$. The results are expressed as B16-hCXCR4-GFP migrated toward CLG/ B16-hCXCR4-GFP migrated toward EG for 3, 7, $14,21,28$ days. Each column represents the mean \pm S.D. $(n=3)$. Statistical analysis of the difference between cells migrated toward CLG and EG at same time point were calculated by Student's t-test. ${ }^{* * *} p<0.001 ;{ }^{* *} p<0.01 ;{ }^{*} p<0.05$ CLG vs EG



Fig. 2 B16-hCXCR4-GFP cells trapped in EG or CLG gels progressively die. In vitro transmigration assay: live /dead B16hCXCR4-GFP cells migrated into EG or CLG for 3, 7, 14, 21, 28 days. Each column represents the mean \pm S.D. $(n=3)$. Statistical significances were calculated by Student's $t$-test. * $p<0.05$ CLG vs EG injected into the mice tail vein. Twenty-two days later mice were euthanized. The gels were recovered, digested and cancer cells characterized as CD45 neg /hCXCR4 plus/ GFP plus cells. The number of CD45neg /hCXCR4plus /GFPplus cells recovered from CLGs was significantly higher than the number of cells isolated from EG (120 \pm 36.7 in CLG vs $16 \pm 6.3$ in EG) (Fig. 3, upper panel). In Fig. 3 (lower panel) representative dot plots for CD45neg /hCXCR4plus /GFPplus cells isolated from EG (panel A) and CLG (panel B) are shown.

\section{CLG reduced tumor burden in solid organs}

To investigate the impact of gel trapped cells in secondary lung colonization, lung metastasis were evaluated. Lung analysis confirmed metastases reduction in mice carrying CLG versus EG $(2.5 \pm 1.3$ versus $5.9 \pm 1$ metastatic lesions per section) (Fig. 4A). In Fig. 4B representative recovered lungs and corresponding subcutaneous gels were shown (EG; a-d, and CLG; e-h). A higher number and larger size of lung metastasis was 


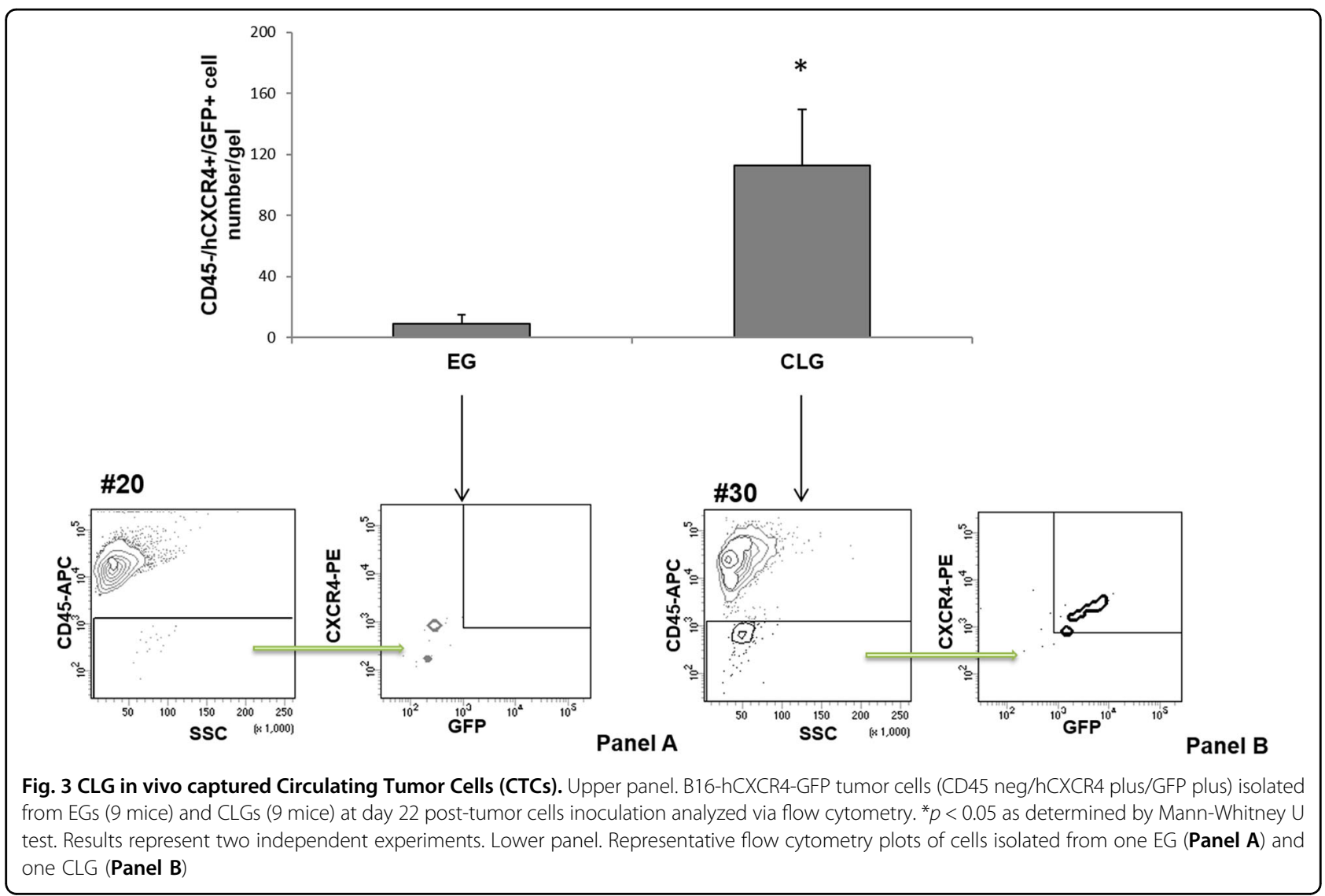

detected in mice carrying EG (Fig. 4B, panel c, d), as compared to mouse carrying CLG (Fig. 4B, panel g, h). Conversely, although EG and CLG trapped cells developed metastasis-like lesions (Fig. 4B, panel a, b, e, f), the nodules developed within the EG (Fig. 4B, panel b) were smaller (Fig. 4B, panel f).

\section{CLG is infiltrated by inflammatory cells}

To analyze the milieu within the gels, infiltrating cells were characterized. EG and CLG were analyzed "in vivo" $24 \mathrm{~h}$ post gels implantation, before of tumor cell inoculation, $-72 \mathrm{~h}$ post cell inoculation and -21 days post cell inoculation. In Fig. 5A higher cell infiltration was detected in CLG as compared to EG already at $24 \mathrm{~h}$ post implantation. Higher infiltrate was detected at $72 \mathrm{~h}$ and 21 days post B16-hCXCR4-GFP inoculation. As shown in Fig. 5A infiltrating cells efficiently migrated toward CLG at 24, $72 \mathrm{~h}$ and 21 days (EG: 0.0 vs CLG: 110 at $24 \mathrm{~h}, n=2$; EG: $21 \pm 9.71$ vs CLG: $89 \pm 21$ at $72 \mathrm{~h}, n=3$; EG: $96 \pm 39.9$ vs CLG: $247 \pm 94.9$ at 21 days, $n=5$ ). Immunohistochemical evaluation of EG/CLGs at day 21 post-B16-hCXCR4-GFP inoculation demonstrated that neutrophils (identified as Ly6G+) and monocytes/macrophages (identified as F4/80 +) efficiently infiltrated CLG (Fig. 5B). In Fig. 5C- Upper left panel, at day 3 and Upper right panel, day 21 post-
B16-hCXCR4-GFP inoculation flow cytometric analysis demonstrated higher density of CD45-positive leukocytes in CLG compared to EG; in particular, CLG displayed higher number of neutrophils $(\mathrm{CD} 11 \mathrm{~b}+\mathrm{Ly} 6 \mathrm{G}+)$ and myeloid (CD11b+/Ly6G-) cells as compared to EG. CD11b+Ly6G+ and CD11b+/Ly6G- cells have been implicated in pre-metastatic niche ${ }^{41,42}$. Conversely, in the Fig. 5C- Lower panel, CD45-positive leukocytes were comparable in EG or CLG 21 days post-B16-GFP inoculation suggesting that CLG recruited CXCR4+tumor cells may affect the recruitment of immune cells ${ }^{41}$.

\section{In vitro characterization of $\mathrm{CLG} / \mathrm{EG}$ recovered cells}

Cells recovered from EG and CLG are shown in Fig. 6A at 3-7 days of cell culture. Cells isolated from CLG displayed spherical shape (Fig. 6A, Panel B), stained positive for $\mathrm{c}-\mathrm{Kit}^{43}$, negative for Alpha-Smooth Muscle Actin $(\alpha-$ SMA) (Fig. 6B), conversely EG recovered cells shaped as fibroblasts (Fig. 6A, Panel A) and stained negative for cKit, positive for $\alpha$-SMA (Fig. 6B). In addition, c-kit and $\alpha$ SMA expression was evaluated on CLG- and EG- isolated cells through qRT-PCR confirming high expression of $\alpha$ SMA and low c-kit in EG, and high expression of c-kit and low $\alpha$-SMA in CLG (Supplemental Fig. 4A). CLG isolated cells appeared epithelial, melanin rich (Fig. 6A, Panel B), 


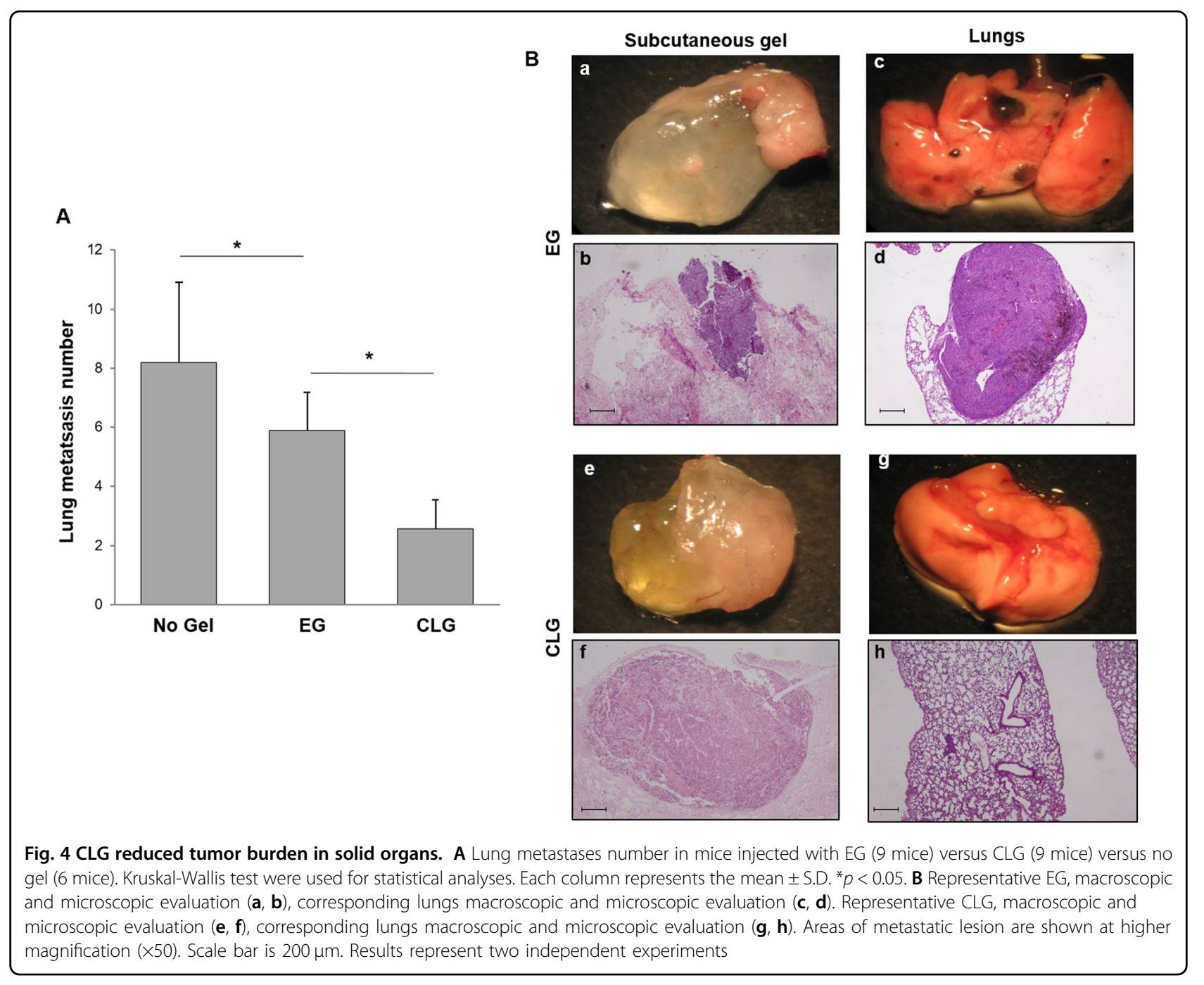

express the Melan $\mathrm{A}^{44}$ and $\mathrm{S} 100{ }^{45}$ suggesting a melanoma cell line (Fig. 6C) while EG isolated cells appeared negative for Melan A and S100 (Fig. 6C). In Fig. 5D the CLG recovered cells expressed human CXCR4 as compared to the injected cells B16-hCXCR4 cells and to PES43, human melanoma cells. As shown in Supplemental Fig. 4B, CLG recovered cells expressed GFP RNA level as compared with B16-hCXCR4-GFP cells. The CLG isolated cells actively migrated toward CXCL12 and migration is inhibited by AMD3100 (Supplemental Fig. 4C). The ability to isolate tumor cells while subtracting them to conventional sites of metastasis allows isolation and characterization of circulating tumoral cells.

\section{CTCs in mice carrying CLG/EG}

The possible impact of CLG and EG on the number of circulating tumor cells (CTCs) was evaluated at 10 and at 22 days post cell injection. Briefly $100 \mu \mathrm{l}$ of retrorbital blood was obtained and CTCs identified as CD45 neg/
hCXCR4 pos/GFP pos. The number of CTCs isolated in mice CLG carrying was significantly higher compared to CTCs retrieved in mice EG carrying. As shown in Fig. 7 (upper-left panel) higher number of CTCs was detected in the blood at 10 days from mice CLG $(0.09 \pm 0.02 \%)$ versus EG $(0.03 \pm 0.02 \%)$. This difference, although lower, is still significant at 22 days (CLG $0.04 \pm 0.01 \%$ versus EG $0.02 \pm$ $0.01 \%$ ) (Fig. 7, lower-left panel). In concordance, GFP mRNA was higher in CTCs isolated from CLG compared to EG carrying mice at 10 and 22 days (respectively, CLG $0.02 \pm 0.009 \%$ versus EG $0.01 \pm 0.003 \%$ and CLG 9.7E$04 \pm 0.002 \%$ versus EG 2.7E-05 $\pm 2.3 \mathrm{E}-05 \%$ ) (Fig. 7 , right panel).

\section{CXCL12 increased in mice carrying CLG/EG}

To investigate on possible mechanisms responsible for increased numbers of CTCs in CLG, circulating CXCL12 was evaluated in peripheral blood collected from CLG/EG bearing $\mathrm{C} 57 \mathrm{Bl} / 6$ mice. As shown in Fig. 8, both CLG and 


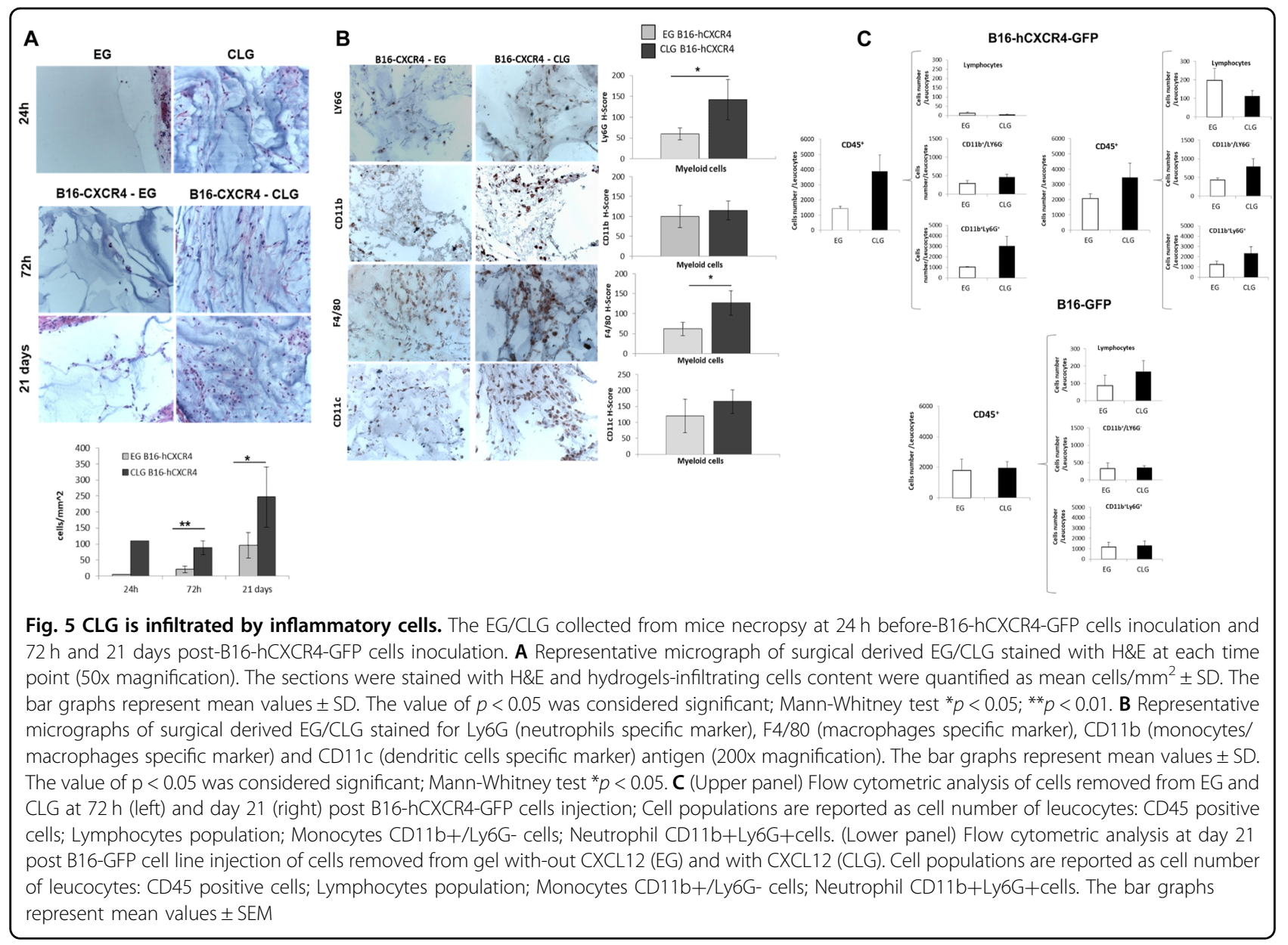

EG carrying mice displayed higher murine CXCL12 plasma level at $24 \mathrm{~h}$ after gel inoculation consistent with inflammatory reaction induced by gel implantation. Circulating CXCL12 at $24 \mathrm{~h}$ was $11.3 \pm 0.2 \mathrm{ng} / \mathrm{ml}$ in mice carryng EG and $10.2 \pm 0.4 \mathrm{ng} / \mathrm{ml}$ in mice carryng CLG compared to $1.1 \pm 0.3$ in gel-not injected mice $(p<0.01)$. CXCL12 blood concentration was not statistically different between mice EG or CLG-inoculated at $24 \mathrm{~h}$ post gel implantation. In both groups, reduction of blood CXCL12 was observed at $72 \mathrm{~h}$ and 21 days post B16-hCXCR4-GFP cells inoculation (at $72 \mathrm{~h} \mathrm{CXCL12} \mathrm{was} 10.6 \pm 0.3 \mathrm{ng} / \mathrm{ml}$ in EG -mice and $7.7 \pm 1.0 \mathrm{ng} / \mathrm{ml}$ in CLG- mice while at 21days CXCL12 was $7.1 \pm 1.8 \mathrm{ng} / \mathrm{ml}$ and $4.1 \pm 2.0 \mathrm{ng} / \mathrm{ml}$ respectively, in EG and CLG-mice) suggesting that plasma CXCL12 was not influencing the propensity of tumor cell homing to the lungs/CLG.

\section{Discussion}

With the primary intent to collect circulating tumor cells expressing CXCR4, a new device composed of a commercially available dermal filler, hyaluronic acid based gel (Belotero Intense ${ }^{\circledast}$ ), loaded with CXCL12 was realized. The CXCL12-loaded gel (CLG) attracted circulating
CXCR4 positive melanoma cells diverting them from secondary sites. The cells isolated from CLG mimicked the original injected cells and could be expanded in vitro providing a valid source of tumor cells for further characterization. Moreover, the CLG, capturing CTCs and diverting them from conventional metastatic sites, induced a net decrease in lung metastases. Interestingly, an increased number of circulating tumor cells (CTCs) were observed in CLG bearing mice. Mechanical devices impairing metastases were previously described ${ }^{39,42,46-48}$. To mimic a functional and reproducible bone, silk scaffolds coupled with bone morphogenetic protein-2 (BMP2) seeded with bone marrow stromal cells (BMSC) were developed ${ }^{46}$. Similarly, a chimeric bone construct was realized with biodegradable tubular composite scaffolds seeded with human mesenchymal progenitor cells and loaded with osteogenic protein- $1^{47}$. Although these examples provided "proof of principle" for a bioengineered humanized model of bone metastasis, the clinical translation is complex. A sort of pre-metastatic niche was developed with a 3D-scaffold embedded with exosomes (M-Trap) capturing human ovarian cancer cells disseminated in the peritoneal cavity ${ }^{39}$. This model 


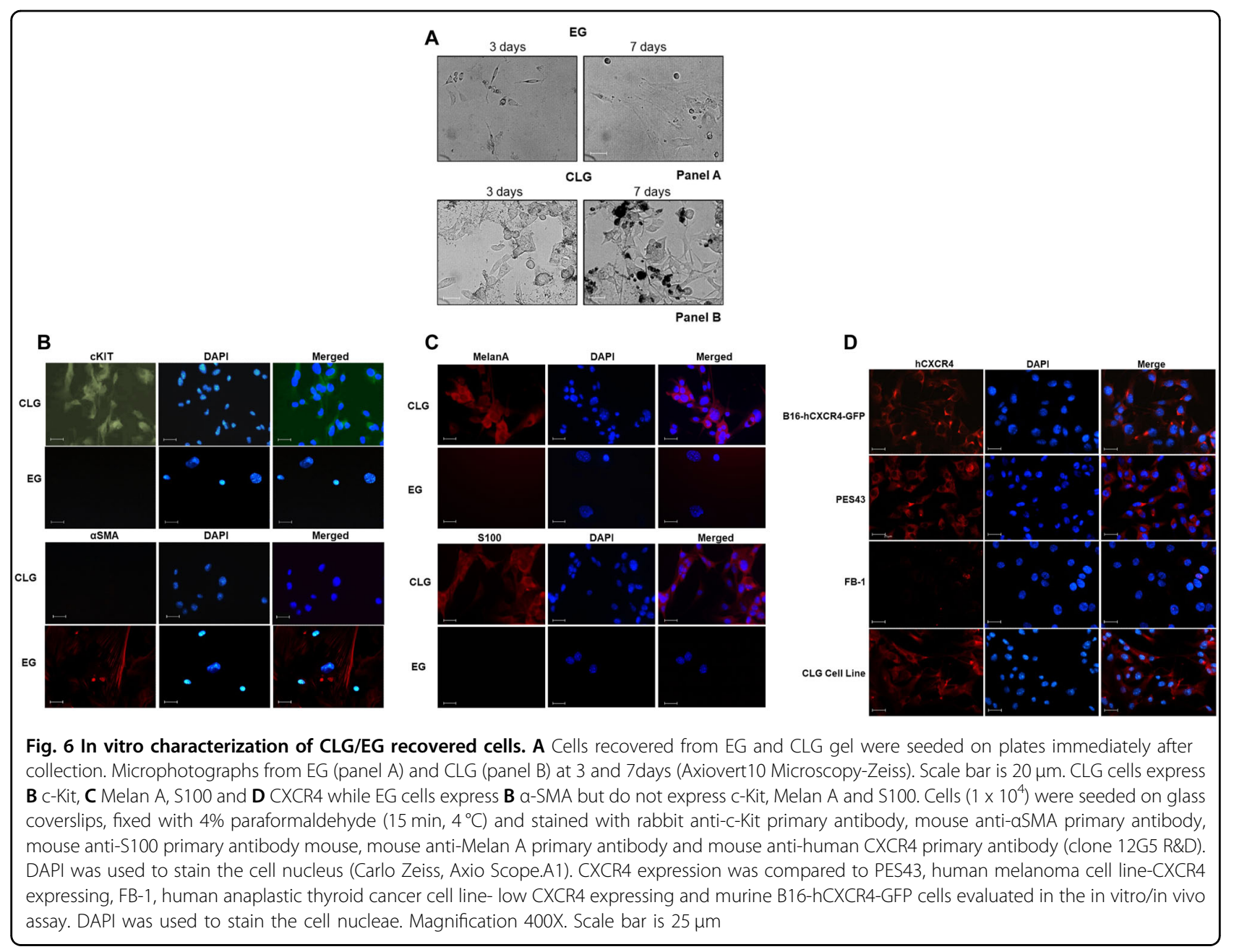

demonstrated that an added matrix could segregate metastatic tumor cells in a defined environment such as peritoneal cavity. Micro particles (MPs) containing carcinoma-associated fibroblasts (CAFs), which continuously deposit a pro-adhesive matrix at the surface, selectively bound ovarian neoplastic cells within the peritoneal compartment of the $\mathrm{MPs}^{48}$. In a xenograft model of breast cancer an implanted biomaterial (PLG) scaffold recruited circulating metastatic breast cancer cells (MDA-MB-231BR $)^{42,49}$ and human breast cancer brain metastasis derived three-dimensional CAFs aggregates expressed significantly higher levels of CXCL12 and CXCL16 than CAFs aggregates generated from primary breast tumors or normal breast, suggesting that chemokine modulation is crucial in regulating metastasis ${ }^{1}$.

The herein described tool CLG represents an innovative and simple solution to trap circulating tumor cells and, secondarily, to reduce lung metastasis. The main hypothesis herein was that interfering in the process that drives tumor cells from tumor to secondary organs, we may reduce the number of effective cells able to develop metastasis. Metastasis development is a very inefficient process with $0.01 \%$ or less of circulating tumor cells able to develop secondary tumors ${ }^{50}$. The CXCL12 gel will subtract CXCR4 overexpressing cells and trap them in a pseudo-niche, where the cells will eventually die within 2 weeks. In doing so it might reduce the critical number of metastasis initiating cells. We may also hypothesize that 'sensing' of CXCL12 inside the gel increases the "signal noise" attracting CXCR4 positive cells and affecting seeding in secondary organs as demonstrated by the largest number of circulating cells detected in mice carrying CLG. Since the hyaluronic acid of the hydrogel exerts itself an effect of pseudo-niche, we expect that the cells will be trapped also there. This is consistent with the reduction of metastases in EG compared to the number of metastasis developed in mice in absence of gel (5.9 versus 8.2 metastatic lesions per section). Interestingly, recent evidence demonstrated that local delivery of lauroylgemcitabine lipid nanocapsule based hydrogel (GemC12LNC) in the tumor resection cavity of glioblastoma could prevent local recurrence ${ }^{51}$. The CXCL12 loaded hydrogels 


\section{Day 10}
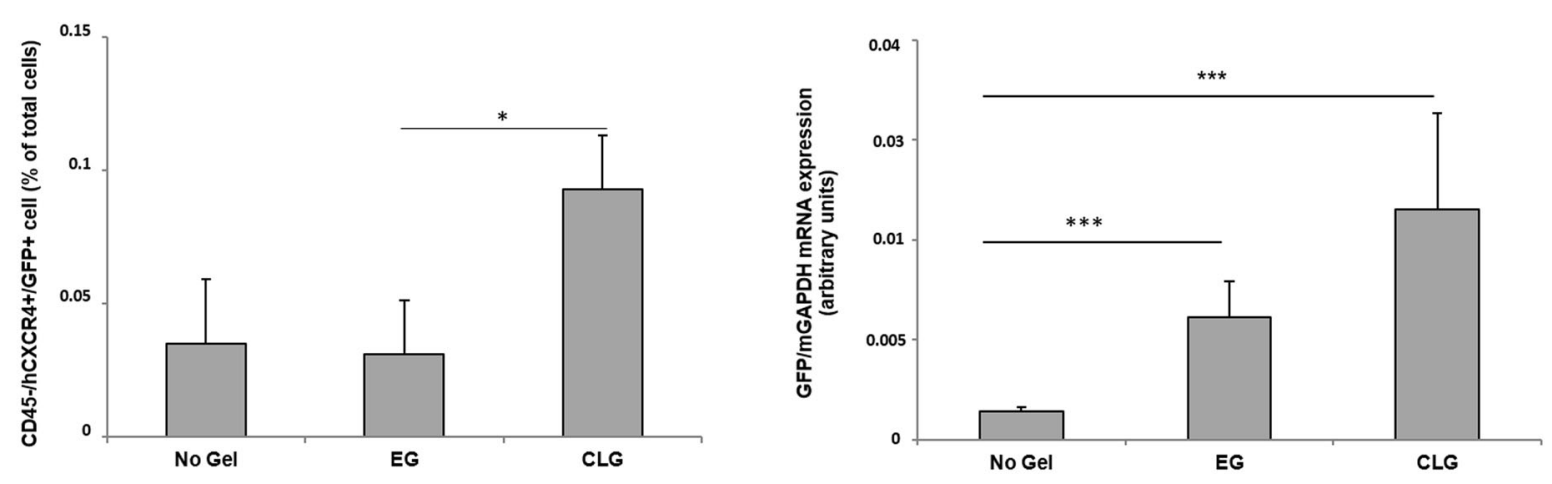

Day 22
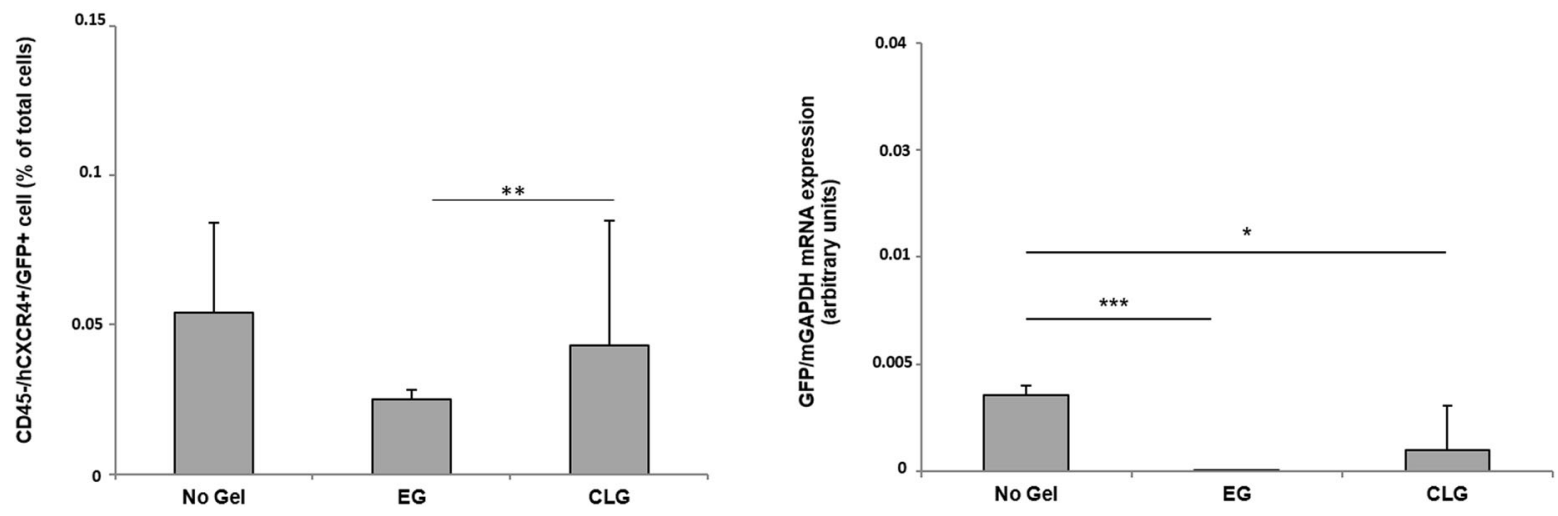

Fig. 7 CTCs in mice carrying CLG/EG. Blood CTCS (CD45 neg/hCXCR4 pos/GFP pos) in mice carrying- EG (9 mice) and -CLG (9 mice) versus no gel (6 mice) at day 10 (upper panel) and day 22 (lower panel) post iv B16-hCXCR4-GFP cells injection. CTCs were identified as CD45neg hCXCR4pos GFPpos cells (left) and GFP gene expression (right). ${ }^{*} p<0.05 ;{ }^{* *} p<0.01 ;{ }^{* * *} p<0.001$ as determined by Mann-Whitney $U$ test. Results represent two independent experiments

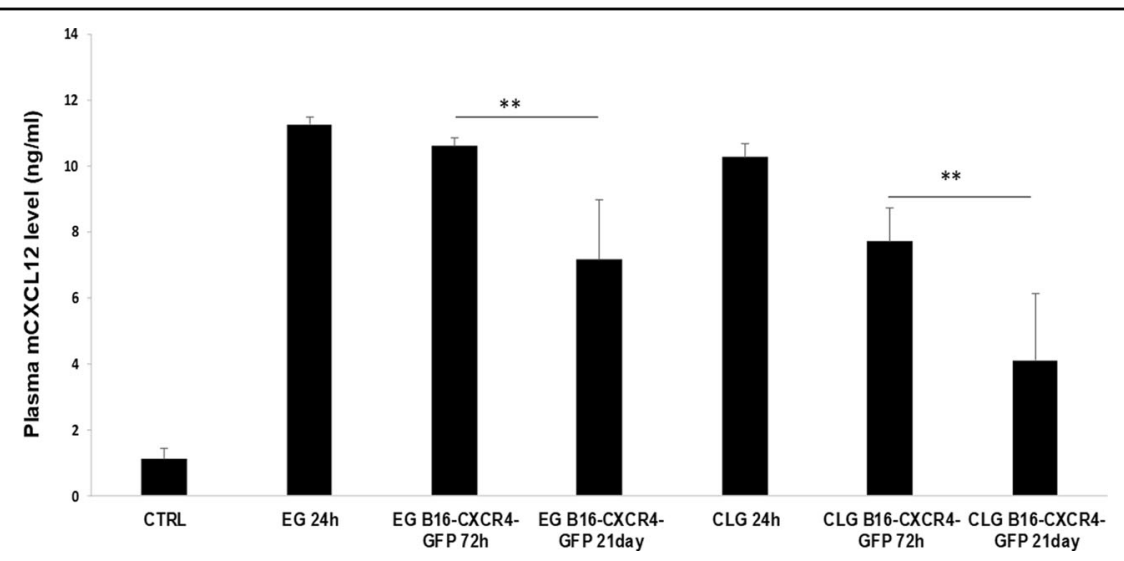

Fig. 8 CXCL12 increased in mice carrying CLG/EG. Plasma of mice carrying- EG and -CLG was collected at day 0 from gel-not injected mice, at $24 \mathrm{~h}$ after gel inoculation before B16-hCXCR4-GFP cells inoculation; at $72 \mathrm{~h}$ or day 21 post cells inoculation and levels of murine CXCL12 were analyzed by ELISA. ${ }^{* *} p<0.01$, as determined by Student's $t$ test. Results represent two independent experiments 
in adjuvant setting may trap the undetectable, occult and harboring micrometastases cells reducing future recurrences. This is based on the capability of the matrix, dermal filler, plus the properties of CXCL12 to develop a suitable pre-metastatic niche with attractive capability for CXCR4 expressing circulating tumor cells. VEGFR1+ hematopoietic precursor cells, along with fibronectin and associated stromal cells modify the local microenvironment and regulate the homing and retention of hematopoietic precursor cells as well as tumor cells ${ }^{17,52}$. Liu et al. developed a CXCL12 biomimetic tumoral niche with a thin and soft polyelectrolyte film. CXCL12 presentation was spatially controlled at the ventral side of breast cancer cells inducing lamellipodia and filopodia mediated by CXCR4. CD44 acted in concert to drive a specific matrixbound CXCL12-induced cell response associated with ERK signaling ${ }^{53}$. Herein CLG recruited higher number of cells compared to EG; although at lesser extent, EG was also able to recruit circulating cancer and mesenchymal cells suggesting that the hyaluronate matrix exerts attraction $^{21,22,54,55}$. Ko Cy et al. developed in vivo model to investigate inflammation-mediated cancer metastasis through biomaterial microspheres. Interestingly, metastatic cancer cells B16F10 injected into the peritoneal cavity migrated into subcutaneous microsphere ${ }^{56}$. The immune cells recruitment to implanted biomaterials may be different in tumor bearing animals versus healthy animals $^{42}$. In our manuscript the CXCL12 loaded gel was able to recruit and trap B16-hCXCR4-GFP cells as previously shown ${ }^{57}$. Quantitative and qualitative differences were detected within the CLGs and EGs inflammatory infiltrate. CLG showed higher number of CD45-positive leukocytes mainly neutrophils CD11b+Ly6G+cells, myeloid CD11b+Ly6G- cells and macrophages F4/80 as compared to $\mathrm{EG}^{58}$. CXCL12 insists also on CXCR7, which is phylogenetically closely related to chemokine receptors, binds CXCL12 with a higher affinity than CXCR4, but fails to couple with $\mathrm{G}$ proteins to induce typical chemokine receptor-mediated cellular responses ${ }^{59}$. Although in our gels CXCR7 antagonism is not able to interfere with migration of CXCR4 expressing cells toward CLG/EGs, it was recently demonstrated that CXCR7 is expressed on $\mathrm{CD} 14^{+} \mathrm{CD} 16^{+}$mature monocytes and a small molecule CXCR7 antagonist (CCX771) can prevent $\mathrm{CD} 14^{+} \mathrm{CD} 16^{+}$ monocyte transmigration into the central nervous system from uninfected and HIV infected individuals ${ }^{60}$. Intriguingly, the number of CTCs isolated in mice carrying CLG was significantly higher compared to CTCs retrieved in mice carrying EG. To better define this phenomenon blood CXCL12 was evaluated but CXCL12 clearly increased in mice gels-inoculated, either empty or CXCL12-loaded consistent with inflammation gels induced. In both groups, EG/CLG-inoculated, reduction of blood CXCL12 was observed at $72 \mathrm{~h}$ and 21 days post
B16-hCXCR4-GFP cells inoculation suggesting that plasma CXCL12 was not influencing the propensity of tumor cell homing to the lungs/CLG. Bertolini et al. defined lung cancer initiating cells (CICs) as CD133 + CXCR4+cells with metastatic potential inhibited by CXCR4 antagonism ${ }^{61}$. In fact CTC enumeration and CXCR4 expression are promising prognostic biomarkers for CTCs in Extensive-Disease Small Cell Lung Cancer (ED-SCLC) at baseline and post-treatment ${ }^{62}$. For patients at risk of recurrence, CLGs would allow characterization of CTCs and praecox recognition of metastasis disease. CTCs isolation is still a high unmet need due to the limited number of cells generally retrieved $\left(1\right.$ in $10^{9}$ red blood cells $)^{63}$. Injecting $1 \times 10^{6}$ of mouse breast cancer GFP-Luc-4T1 in tail vein of BALB/c syngeneic mice resulted in detection of 16 Luc-CTCs comparing three CTC detection methods ${ }^{64}$. The patient subcutaneous devices implantation is currently evaluated in clinical trials. Agarose devices containing murine renal cancer cells (RENCA cells) were safely inoculated in patients abdominal cavity. RENCA cells, encapsulated in the agarose gel, selected a stem cell-like subpopulation which drove colony formation in the macrobeads and produced diffusible substances that markedly inhibited in vitro and in vivo proliferation of epithelial-derived tumor cells outside the macrobeads ${ }^{65}$ (NCT02046174). Phase II studies in patients with colorectal, pancreatic or prostate cancers are in progress (NCT01174368, NCT01053013). In conclusion, our study shows that a commercially available dermal filler loaded with CXCL12 is able to capture and divert neoplastic CXCR4 expressing cells. Behind the suggestion of a diminution of the metastatic efficiency, it is possible to speculate that the device will allow identification and characterization of potential metastatic cells. The praecox identification and definition of metastatic cells may enable efficient interventional strategies.

\section{Acknowledgements \\ We thank Dr. Jane Bryce for text revision. \\ Author details \\ 1Functional Genomics, Istituto Nazionale Tumori - IRCCS - Fondazione "G. Pascale", Napoli, Italy. 'Department of Pharmacy, Federico II University, Napoli, Italy. ${ }^{3}$ Animal Facility, Istituto Nazionale Tumori - IRCCS - Fondazione "G. Pascale", Napoli, Italy. "Pathology Unit, Istituto Nazionale Tumori - IRCCS - Fondazione "G. Pascale", Napoli, Italy. ${ }^{5}$ Department of Advanced Biomedical Sciences, Federico II University School of Medicine, Napoli, Italy}

Conflict of interest

The authors declare that they have no conflict of interest.

\section{Publisher's note}

Springer Nature remains neutral with regard to jurisdictional claims in published maps and institutional affiliations. 
Supplementary Information accompanies this paper at (https://doi.org/ 10.1038/s41419-019-1796-6).

Received: 12 December 2018 Revised: 2 July 2019 Accepted: 4 July 2019 Published online: 22 July 2019

\section{References}

1. Chung, B. et al. Human brain metastatic stroma attracts breast cancer cells via chemokines CXCL16 and CXCL12. NPJ breast cancer 3, 6 (2017).

2. Valastyan, S. \& Weinberg, R. A. Tumor metastasis: molecular insights and evolving paradigms. Cell 147, 275-292 (2011).

3. Guo, F. et al. CXCL12/CXCR4: a symbiotic bridge linking cancer cells and their stromal neighbors in oncogenic communication networks. Oncogene $\mathbf{3 5}$, 816-826 (2016)

4. Tokoyoda, K., Egawa, T., Sugiyama, T., Choi, B. I. \& Nagasawa, T. Cellular niches controlling B lymphocyte behavior within bone marrow during development. Immunity 20, 707-718 (2004)

5. Ziegler, M. E., Hatch, M. M., Wu, N., Muawad, S. A. \& Hughes, C. C. mTORC2 mediates CXCL12-induced angiogenesis. Angiogenesis 19, 359-371 (2016).

6. Scala, S. Molecular Pathways: Targeting the CXCR4-CXCL12 Axis-Untapped Potential in the Tumor Microenvironment. Clin. Cancer Res. : Off. J. Am. Assoc Cancer Res. 21, 4278-4285 (2015).

7. Balkwill, F. The significance of cancer cell expression of the chemokine receptor CXCR4. Semin. cancer Biol. 14, 171-179 (2004).

8. Chatterjee, S., Behnam Azad, B. \& Nimmagadda, S. The intricate role of CXCR4 in cancer. Adv. cancer Res. 124, 31-82 (2014).

9. Zlotnik, A. New insights on the role of CXCR4 in cancer metastasis. J. Pathol. 215, 211-213 (2008)

10. Sun, X. et al. CXCL12 / CXCR4 / CXCR7 chemokine axis and cancer progression. Cancer Metastas-. Rev. 29, 709-722 (2010).

11. Hernandez, L., Magalhaes, M. A., Coniglio, S. J., Condeelis, J. S. \& Segall, J. E. Opposing roles of CXCR4 and CXCR7 in breast cancer metastasis. Breast cancer Res. : $B C R$ 13, R128 (2011).

12. lerano, $C$. et al. CXCR4 and CXCR7 transduce through mTOR in human renal cancer cells. Cell death Dis. 5, e1310 (2014).

13. Yamamura, Y. et al. Akt-Girdin signaling in cancer-associated fibroblasts contributes to tumor progression. Cancer Res 75, 813-823 (2015).

14. Peinado, H. et al. Pre-metastatic niches: organ-specific homes for metastases. Nat. Rev. Cancer 17, 302-317 (2017).

15. Liu, Y. \& Cao, X. Characteristics and significance of the pre-metastatic niche Cancer Cell 30, 668-681 (2016).

16. Hiratsuka, S., Watanabe, A., Aburatani, H. \& Maru, Y. Tumour-mediated upregulation of chemoattractants and recruitment of myeloid cells predetermines lung metastasis. Nat. cell Biol. 8, 1369-1375 (2006).

17. Peinado, H., Lavotshkin, S. \& Lyden, D. The secreted factors responsible for premetastatic niche formation: old sayings and new thoughts. Semin. cancer Biol. 21, 139-146 (2011)

18. Seubert, B. et al. Tissue inhibitor of metalloproteinases (TIMP)-1 creates a premetastatic niche in the liver through SDF-1/CXCR4-dependent neutrophil recruitment in mice. Hepatology 61, 238-248 (2015).

19. Lortat-Jacob, $\mathrm{H}$. The molecular basis and functional implications of chemokine interactions with heparan sulphate. Curr. Opin. Struct. Biol. 19, 543-548 (2009).

20. Purcell, B. P., Elser, J. A., Mu, A., Margulies, K. B. \& Burdick, J. A. Synergistic effects of SDF-1alpha chemokine and hyaluronic acid release from degradable hydrogels on directing bone marrow derived cell homing to the myocardium. Biomaterials 33, 7849-7857 (2012).

21. Fuchs, K. et al. Opposing effects of high- and low-molecular weight hyaluronan on CXCL12-induced CXCR4 signaling depend on CD44. Cell death Dis. 4 e819 (2013).

22. Avigdor, A. et al. CD44 and hyaluronic acid cooperate with SDF-1 in the trafficking of human CD34+ stem/progenitor cells to bone marrow. Blood 103, 2981-2989 (2004).

23. Netelenbos, T. et al. Proteoglycans guide SDF-1-induced migration of hematopoietic progenitor cells. J. Leukoc. Biol. 72, 353-362 (2002).

24. Toole, B. P. Hyaluronan: from extracellular glue to pericellular cue. Nat. Rev. Cancer 4, 528-539 (2004).

25. Misra, S., Hascall, V. C., Markwald, R. R. \& Ghatak, S. Interactions between hyaluronan and its receptors (CD44, RHAMM) regulate the activities of inflammation and cancer. Front. Immunol. 6, 31 (2015).
26. Mondon K., Dadras M., Tillier J. and Molliard S. G. Influence of the macro and/ or microstructure of cross-linked hyaluronic acid hydrogels on the release of two model drugs. J Glycobiol. 5, 1-7 (2016).

27. Amara, A et al. Stromal cell-derived factor-1alpha associates with heparan sulfates through the first beta-strand of the chemokine. J. Biol. Chem. 274, 23916-23925 (1999).

28. Vagesjo, E. et al. Accelerated wound healing in mice by on-site production and delivery of CXCL12 by transformed lactic acid bacteria. Proc. Natl. Acad. Sci. USA 115, 1895-1900 (2018).

29. Mathew, A. P., Uthaman, S., Cho, K. H., Cho, C. S. \& Park, I. K. Injectable hydrogels for delivering biotherapeutic molecules. Int J. Biol. Macromol. 110 17-29 (2018)

30. Sadir, R., Imberty, A., Baleux, F. \& Lortat-Jacob, H. Heparan sulfate/heparin oligosaccharides protect stromal cell-derived factor-1 (SDF-1)/CXCL12 against proteolysis induced by CD26/dipeptidyl peptidase IV. J. Biol. Chem. 279, 43854-43860 (2004).

31. Jin, L., Hope, K. J., Zhai, Q., Smadja-Joffe, F. \& Dick, J. E. Targeting of CD44 eradicates human acute myeloid leukemic stem cells. Nat. Med 12, 1167-1174 (2006).

32. Kang, Y. T. et al. Cytopathological study of the circulating tumor cells filtered from the cancer patients' blood using hydrogel-based cell block formation. Sci. Rep. 8, 15218 (2018)

33. Miceli, R. et al. New cell block containing agarose for cytopathological diagnosis of tumor samples. Diagn. Cytopathol. 45, 1057-1060 (2017).

34. Meyerholz, D. K. \& Beck, A. P. Principles and approaches for reproducible scoring of tissue stains in research. Lab Invest 98, 844-855 (2018).

35. Portella, L. et al. Preclinical development of a novel class of CXCR4 antagonist impairing solid tumors growth and metastases. PloS ONE 8, e74548 (2013).

36. De Clercq, E. Recent advances on the use of the CXCR4 antagonist plerixafor (AMD3100, Mozobil) and potential of other CXCR4 antagonists as stem cell mobilizers. Pharmacol. Ther. 128, 509-518 (2010).

37. Burns, J. M. et al. A novel chemokine receptor for SDF-1 and I-TAC involved in cell survival, cell adhesion, and tumor development. J. Exp. Med. 203, 2201-2213 (2006)

38. Zabel, B. A. et al. Elucidation of CXCR7-mediated signaling events and inhibition of CXCR4-mediated tumor cell transendothelial migration by CXCR7 ligands. J. Immunol. 183, 3204-3211 (2009).

39. de la Fuente, A. et al. M-Trap: Exosome-based capture of tumor cells as a new technology in peritoneal metastasis. J. Natl. Cancer Inst. https://doi.org/ 10.1093/jnci/djv184 (2015)

40. Sarkar, A., Tatlidede, S., Scherer, S. S., Orgill, D. P. \& Berthiaume, F. Combination of stromal cell-derived factor-1 and collagen-glycosaminoglycan scaffold delays contraction and accelerates reepithelialization of dermal wounds in wild-type mice. Wound Repair Regen. 19, 71-79 (2011).

41. Kitamura, T., Qian, B. Z. \& Pollard, J. W. Immune cell promotion of metastasis. Nat. Rev. Immunol. 15, 73-86 (2015).

42. Rao, S. S. et al. Enhanced survival with implantable scaffolds that capture metastatic breast cancer cells in vivo. Cancer Res. 76, 5209-5218 (2016).

43. Garrido, M. C. \& Bastian, B. C. KIT as a therapeutic target in melanoma. J. Invest Dermatol 130, 20-27 (2010).

44. Ohsie, S. J., Sarantopoulos, G. P., Cochran, A. J. \& Binder, S. W. Immunohistochemical characteristics of melanoma. J. Cutan. Pathol. 35, 433-444 (2008).

45. Aisner, D. L., Maker, A., Rosenberg, S. A. \& Berman, D. M. Loss of S100 antigenicity in metastatic melanoma. Hum. Pathol. 36, 1016-1019 (2005).

46. Moreau, J. E. et al. Tissue-engineered bone serves as a target for metastasis of human breast cancer in a mouse model. Cancer Res. 67, 10304-10308 (2007).

47. Holzapfel, B. M. et al. Species-specific homing mechanisms of human prostate cancer metastasis in tissue engineered bone. Biomaterials 35, 4108-4115 (2014).

48. De Vlieghere, E. et al. Tumor-environment biomimetics delay peritoneal metastasis formation by deceiving and redirecting disseminated cancer cells. Biomaterials 54, 148-157 (2015).

49. Azarin, S. M. et al. In vivo capture and label-free detection of early metastatic cells. Nat. Commun. 6, 8094 (2015).

50. Hamilton, G., Rath, B. Circulating Tumor Cells in the Parallel Invasion Model Supporting Early Metastasis. Oncomedicine. 3, 15-27 (2018).

51. Bastiancich, C. et al. Injectable nanomedicine hydrogel for local chemotherapy of glioblastoma after surgical resection. J. Control. Release. 264, 45-54 (2017).

52. Kaplan, R. N. et al. VEGFR1-positive haematopoietic bone marrow progenitors initiate the pre-metastatic niche. Nature 438, 820-827 (2005). 
53. Liu, X. Q. et al. Biomaterial-enabled delivery of SDF-1alpha at the ventral side of breast cancer cells reveals a crosstalk between cell receptors to promote the invasive phenotype. Biomaterials 127, 61-74 (2017).

54. Zhu, H. et al. The role of the hyaluronan receptor CD44 in mesenchymal stem cell migration in the extracellular matrix. Stem Cells 24, 928-935 (2006).

55. Lei, Y., Gojgini, S., Lam, J. \& Segura, T. The spreading, migration and proliferation of mouse mesenchymal stem cells cultured inside hyaluronic acid hydrogels. Biomaterials 32, 39-47 (2011).

56. Ko, C. Y. et al. The use of chemokine-releasing tissue engineering scaffolds in a model of inflammatory response-mediated melanoma cancer metastasis. Biomaterials 33, 876-885 (2012).

57. Giarra, S. et al. Engineering of thermoresponsive gels as a fake metastatic niche. Carbohydr. Polym. 191, 112-118 (2018).

58. Markowitz, J., Wesolowski, R., Papenfuss, T., Brooks, T. R. \& Carson, W. E. 3ro Myeloid-derived suppressor cells in breast cancer. Breast Cancer Res Treat. 140 13-21 (2013).

59. Rajagopal, S. et al. Beta-arrestin- but not G protein-mediated signaling by the "decoy" receptor CXCR7. Proc. Natl. Acad. Sci. USA 107, 628-632 (2010).
60. Veenstra, M. et al. Frontline Science: CXCR7 mediates CD14+CD16+ monocyte transmigration across the blood brain barrier: a potential therapeutic target for NeuroAIDS. J. Leukoc. Biol. https://doi.org/10.1189/jlb.3HI0517-167R (2017).

61. Bertolini, G. et al. Highly tumorigenic lung cancer CD133+ cells display stemlike features and are spared by cisplatin treatment. Proc. Natl. Acad. Sci. USA 106, 16281-16286 (2009).

62. Salgia, R. et al. Prognostic and predictive value of circulating tumor cells and CXCR4 expression as biomarkers for a CXCR4 peptide antagonist in combination with carboplatin-etoposide in small cell lung cancer: exploratory analysis of a phase II study. Investig. new drugs 35, 334-344 (2017).

63. Cohen, S. J. et al. Prognostic significance of circulating tumor cells in patients with metastatic colorectal cancer. Ann. Oncol. 20, 1223-1229 (2009).

64. $\mathrm{Xu}, \mathrm{W}$. et al. Comparison of three different methods for the detection of circulating tumor cells in mice with lung metastasis. Oncol. Rep. 37, 3219-3226 (2017).

65. Smith, B. H. et al. Hydrophilic agarose macrobead cultures select for outgrowth of carcinoma cell populations that can restrict tumor growth. Cancer Res. 71, 725-735 (2011) 